C) 2007 JLO (1984) Limited

doi:10.1017/S002221510700802X

Printed in the United Kingdom

First published online 1 May 2007

\title{
Standards for ethical publication
}

In a previous editorial the editors of The Journal of Laryngology and Otology presented the Journal's position with regard to ethical standards in medical publication. ${ }^{1}$ One of the developments recently introduced is a joint commitment by editors of journals of Otolaryngology to act in a coordinated manner in order to share information when a suspected breach of publishing integrity has occurred. The following statement from the Consortium of Editors of Otolaryngology Journals documents this approach and is complementary to the JLO's formal policy, which is reproduced on the Journal's website: www.jlo.co.uk

It is essential that authors involved in biomedical publication be aware of basic guidelines for the ethical publication of their scientific work. The undersigned editors have taken a consortium approach to a concern facing several major journals, which relates to duplicate publication. We aim to maintain the integrity of our scientific journals. Reports that claim original information must contain original information. We believe the priority placed on this tenet is appropriately reflective of its importance to patient care.

Authors are ethically obligated to be sure that data are presented accurately and in a fair and unbiased way. The supporting data for any scientific investigation should be maintained in the office files for a minimum of five to seven years after publication (this is dependent on the study and the governing agency; some institutions require less, particularly for retrospective data). Scientific data should never be altered or deleted. In this era of modern computer science, authors must also be careful that photographs and other illustrations, when enhanced or otherwise 'touched up', do not mislead readers or distort information. Digital enhancement of pictures which might be interpreted as intending to adjust or enhance findings or which could otherwise potentially mislead the reader is considered a major ethical breach.

Scientific data may not be published twice without clear notification, to the editor-in-chief, reviewing editor, editorial staff and the readership of the journal, that these data have been published previously. Duplicate submission or redundant publication of a similar data set is considered unethical. ${ }^{2-9}$ 'Duplicate submission' occurs when an author submits a manuscript simultaneously to two or more journals. This is inappropriate unless the journal editors have decided in advance that redundant publication would be in the best interest of the public's health. 'Redundant publication' is publication of a paper that overlaps substantially with one already published in print or electronic media. The overlap may be in data, content or both, but commentary as written still appears to emphasise data.

The fundamental issue with redundant publication is that it violates the trust placed by readers of a journal that content is original unless there is a clear statement to the contrary. It is the senior or corresponding author's responsibility to vet all manuscript data and identify redundant content in advance of submission. When submitting a manuscript, the author should fully disclose to the editor any duplicate submissions or previous publications that could potentially be considered redundant. It is not the responsibility of the editor or manuscript referees to check every reference or search the literature for undisclosed redundancy; the due diligence is the responsibility of the lead author. Also, 'preliminary reporting' can violate journal policies if the author 'leaks' data or original research to the media, industry or government before publication. This should not necessarily jeopardise publication but should be discussed from the outset with the editor and a mutually acceptable approach agreed upon in advance.

Publication of duplicate or redundant data or content in journals of different disciplines or different languages is a violation of this principle. 'Rehash' of an old data set into a new publication is similarly redundant. If ever an author has questions on the interpretation of redundant or duplicate publication, it is his or her responsibility to bring those questions to the attention of the editor-in-chief before the review or publication of the manuscript. Full disclosure will prevent violation of this principle.

The undersigned editors agree that if an author is found by one of the editors to have violated the foregoing standards for ethical publication of scientific work, that editor will share with the other editors the name of the author and details of the violation. Each editor will then independently determine what sanction, if any, he or she will impose on the author with respect to future publication in their respective journals. When indicated, other actions may also be independently undertaken by the respective editors, including, but not limited to, notification of the dean, department chair, or chair of the scientific integrity committee at the author's institution.

This editorial expresses the latest policy of the undersigned editors and clarifies and amends the policy previously set forth in May $2005 .^{10}$ This editorial is being published simultaneously in each of the represented journals to emphasise the importance of this principle and to maximise its accessibility to the community of authors who publish in these 
journals. These principles were developed and supported by the undersigned but are not meant to be restrictive to these journals. We invite other editors of journals in our field to participate in this policy.

\section{References}

1 Youngs R, Kenyon G. Maintaining ethical standards in medical publishing. J Laryngol Otol 2006;120:1-2

2 Kassirer J, Angell M. Redundant publication: a reminder. N Engl J Med 1995;333:449-50

3 Doherty M. The misconduct of redundant publication. Ann Rheum Dis 1996;55:783-5

4 Huston P, Moher D. Redundancy, disaggregation and the integrity of medical research. Lancet 1996;347:1024-6

5 Huth EJ. Repetitive and divided publication. In: Hudson Jones A, McLellan F, eds. Ethical Issues in Biomedical Publication. Baltimore: The Johns Hopkins University Press, 2000;112-36

6 Schein M, Paladugu R. Redundant surgical publication: tip of the iceberg. Surgery 2001;129:655-61

7 Bailey BJ. Duplicate publication in the field of otolaryngology-head and neck surgery. Otolaryngol Head Neck Surg 2002:126:211-16

8 Jackler R. Otology and Neurotology policy on redundant publication. Otol Neurotol 2003;24:131

9 Uniform Requirements for Manuscripts Submitted to Biomedical Journals: Writing and Editing for Biomedical Publication. http://www.icmje.org/\#over [16 October 2006]

10 Benninger MS, Jackler RK, Johnson JT, Johns MM, Kennedy DW, Ruben RJ et al. Consortium of otolaryngology-head and neck surgery journals to collaborate in maintenance of high ethical standards. Head Neck 2005;27:351-2

JONAS T JOHNSON EDITOR, The Laryngoscope
JOHN K NIPAEKO

EDITOR-IN-CHIEF, Otology and Neurotology

PAUL A LEVINE

EDITOR, Archives of Otolaryngology-Head and Neck Surgery

DAVID W KENNEDY

EDITOR, American Journal of Rhinology PETE WEBER

EDITOR-IN-CHIEF, American Journal of Otolaryngology

RANDAL S WEBER

EDITOR, Head and Neck

MICHAEL S BENNINGER

PAST EDITOR-IN-CHIEF, Otolaryngology-Head and Neck Surgery

RICHARD M ROSENFELD

EDITOR-IN-CHIEF, Otolaryngology-Head and Neck Surgery

ROBERT J RUBEN

EDITOR-IN-CHIEF, International Journal of Pediatric Otorhinolaryngology

RICHARD J H SMITH

EDITOR-IN-CHIEF, Annals of Otology, Rhinology and Laryngology

ROBERT THAYER SATALOFF

EDITOR-IN-CHIEF, The Journal of Voice

EDITOR-IN-CHIEF, Ear, Nose and Throat Journal

NEIL WEIR

EDITOR EMERITUS, The Journal of Laryngology and Otology 